\title{
Lafleur, William R., Gernot Bohme and Susumu Shimazono, eds. 2007. Dark medicine: Rationalizing unethical medical research
}

\author{
Bloomington, IND: Indiana University Press., ISBN 9780253348722, pp. 280.
}

\author{
Stanley G. Korenman
}

Received: 10 December 2009 / Accepted: 28 December 2009 /Published online: 2 February 2010

(C) The Author(s) 2010. This article is published with open access at Springerlink.com

Certain books make you reconsider your views even though you really would rather not. This edited collection is one of those. When I was a child I became enamored of science because I could be both intellectually challenged and do unqualified good. While I was thinking those thoughts and reading every science book I could find, the Germans and Japanese were carrying out their murderous experiments in the name of human research.

Dark Medicine illuminates those events with special detail on the Japanese activities in Unit 731, with which we in the West are much less familiar than the Nazi experiments, and asks repeatedly: how did respected physicians of those times and places rationalize their behavior? In each case, the subjects were rendered subhuman (marked for death) and the process was justified by a combination of normalization and intimidation.

American researchers, while recognizing the evils of Hitler's Germany and, in theory, understanding the principles embedded in the Nuremberg Report, carried out numerous unethical research projects involving exposures to radiation and biohazards. In these cases, the research was rationalized by referral to the exigencies of the "Cold War" (the enemy was probably doing the same thing) and normalization of

S. G. Korenman $(\bowtie)$

David Geffen School of Medicine, UCLA,

Los Angeles, CA, USA

e-mail: skorenman@mednet.ucla.edu the behavior as standard. Eventually the disgraceful nature of the studies was made apparent. As noted, by referral to Marcus Aurelius, the medical profession was declared "incapable of acting upright on its own" in human research and had to "be kept upright by proliferating laws and policies."

The second half of the book opens with a discussion of iatrogenesis in medicine (Fox) in which harm is done in order to accomplish good, with the obvious example being surgery. The profession proceeds with progressively more invasive procedures until one must ask: "Is the good worth the harm?" and "who really has the right to decide?" Near-lethal chemotherapy and organ transplantation are realms demonstrating great technological achievement, but at what cost in quality of life and dignity? Fox asks: "Does the technological imperative abide by any limits?"

The authors ask how normalization of technological development in medicine functions in the realm of dying (Komatsu), and brain death and transplantation (Yamaori). There is a worrisome discussion of eugenics in high tech fertility (Ogino) and use of embryos (Shimazono) as procedures that diminish human dignity in the name of technical progress and heightened national research competitiveness. Comparisons are made between preimplantation and fetal eugenics and Nazi ideas of eugenics.

Ogino also discusses the feminist question of whether technological advances liberate women from constraints on desired reproduction or whether they 
simply represent new and invasive ways of exploiting women's bodies. She focuses on differing cultural attitudes in different countries and describes the evolution of thought and policies regarding reproductive technologies in Japan. Japanese women are not enthusiastic about use of these techniques for fertility but want to have children with no identifiable imperfections. Interesting, but not necessarily apt comparisons are made between the family dignity inherent in the old way of death in Japan in comparison to the cold, alienating formalized process associated with brain death for organ transplantation.

In the final chapter, La Fleur-drawing on Hans Jonas' work-asks whether the concept of seeking a biologically determined utopia in which we improve the human genome and vanquish many of today's health problems is actually a desirable end, either for humanity as a whole or for individuals. Utopian thinking implies changes possible mainly in command societies. Someone in charge has to make decisions and see to it that they are implemented. That idea frightens me. To whom would you be willing to entrust such momentous decisions? What would be universally agreed upon changes?

This set of powerful essays sheds light on medicine and its practitioners past, present and future and questions the headlong plunge of developed and developing societies into more and more aggressive technological attacks on illness to preserve life itself. It is truly worthwhile reading. We need to think more carefully about where we are headed as a species and we hope that this book is a harbinger of that deep thought as we, in the United States, prepare to address reform of our healthcare system in the setting of accelerating technological capability and burgeoning costs.

Open Access This article is distributed under the terms of the Creative Commons Attribution Noncommercial License which permits any noncommercial use, distribution, and reproduction in any medium, provided the original author(s) and source are credited. 